\title{
Severe Hypoalbuminemia Following Roux-En-Y Gastric Bypass in a Patient with Type 1 Diabetes
}

\author{
Eva Christina Krzizek*, Johanna Maria Brix and Bernhard Ludvik \\ Department of Medicine 1, Rudolfstiftung Hospital, Vienna \\ Karl Landsteiner Institute for obesity and metabolic diseases, Vienna
}

ISSN: 2578-0263

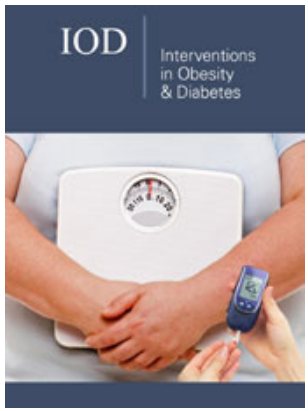

*Corresponding author: Eva Christina Krzizek, Department of Medicine 1, Rudolfstiftung Hospital, Vienna

Submission: 侮 May 01, 2020

Published: 制June 02, 2020

Volume 4 - Issue 2

How to cite this article: Eva Christina Krzizek, Johanna Maria Brix, Bernhard Ludvik. Severe Hypoalbuminemia Following Roux-En-Y Gastric Bypass in a Patient with Type 1 Diabetes. Interventions Obes Diabetes 4(2). IOD.000581. 2020. DOI: 10.31031/IOD.2020.04.000581

Copyright@ Eva Christina Krzizek. This article is distributed under the terms of the Creative Commons Attribution 4.0 International License, which permits unrestricted use and redistribution provided that the original author and source are credited.

\begin{abstract}
Albuminuria in the context of diabetic nephropathy is a known complication of poorly controlled diabetes. Data of the Swedish Obese Study showed a reduction of albuminuria after bariatric surgery. On the other hand, Roux-en-Y gastric bypass carries the risk of protein malabsorption due to changes in the gut anatomy and physiology. In this case report we describe the results of a patient with both, diabetes mellitus type 1 and bariatric surgery. A 49-year old woman (height $157 \mathrm{~cm}$, weight $95 \mathrm{~kg}$, BMI $38.5 \mathrm{~kg} /$ $\mathrm{m}^{2}$ ) with type 1 diabetes since 1983 underwent Roux-en-Y gastric bypass in 2005. She was admitted to our hospital due to generalized edema in December 2017. Routine check-up for bariatric patients was performed including blood tests after an overnight fasting and a urine sample. Amongst others HbA1c, creatinine, albumin and albumin-creatinine-ratio were evaluated. Yearly check-ups of these parameters were evaluated retrospectively since 1999. As expected, there was a significant weight loss after bariatric surgery (2005: $122 \mathrm{~kg}$, BMI $49.4 \mathrm{~kg} / \mathrm{m}^{2} ; 2007: 80 \mathrm{~kg}$, BMI $32.4 \mathrm{~kg} / \mathrm{m}^{2}$ ).
\end{abstract}

Diabetes control has always been poor (HbA1c 8.9\% (1999), 8.7\% (2005), 10.3\% (2007), 10.8\% (2017)). Diabetic nephropathy and retinopathy have been known since 1999. Albuminuria was present before bariatric surgery and got worse over the years (ACR 32.6mg/g (1999), 158mg/g (2005), $2246.4 \mathrm{mg} / \mathrm{g}$ (2014), 1336.1mg/g (2017). Furthermore, hypalbuminemia has been present before surgery and deteriorated subsequently (albumin 29.0\% (1999), 60.6\% (2005), 32.2\% (2012), 21.6\% (2017)). In this patient, albuminuria unexpectedly worsened after Roux-en-Y gastric bypass despite weight loss, most likely due to insufficient metabolic control. Following surgery, decreased protein absorption contributed to the severe hypoalbuminemia resulting in generalized edema. Thus, patients at high risk for hypoalbuminemia, especially those with progressive diabetic nephropathy, need to be carefully evaluated preoperatively and be offered non-malabsorptive bariatric procedures such as sleeve gastrectomy, if indicated.

Keywords: Severe hypalbuminemia; Roux-En-Y-gastric bypass; Diabetes mellitus type 1; Macro albuminuria

Abbreviations: RYGB: Roux-En-Y Gastric Bypass; BPD: Bilio Pancreatic Diversion; BMI: Body Mass Index; A1C: Hemoglobin A1c; ACR: Albumin/Creatinine Ratio; SOS: Swedish Obese Study

\section{Introduction}

Patients with diabetes mellitus are at risk for several long-term complications due to insufficient diabetes control. Increased albuminuria is considered to be an early sign of diabetic nephropathy and is associated with an elevated risk for cardiovascular disease and early mortality [1,2]. Albuminuria usually occurs in association with poor glycemic control, elevated blood pressure and longer diabetes duration [3]. 30-40\% of patients with type 1 diabetes develop microalbuminuria [4,5]. In type 2 diabetes, ten years from diagnosis the prevalence of microalbuminuria is $24.9 \%$ [6]. During the last decades bariatric surgery for morbid obese patients became more and more frequent. Between 2014 and 2018 there were 190.177 of primary bariatric surgeries performed worldwide [7]. $69.2 \%$ of these patients were diagnosed with diabetes [7]. Besides significant weight reduction, beneficial effects of bariatric surgery comprise (transient) remission of type 2 diabetes and improvement of other risk factors such as hypertension and hyperlipidemia [8]. Therefore, bariatric surgery is mentioned as a potential treatment in obese, type 2 diabetic subjects in current guidelines $[9,10]$. Regarding albuminuria, data from the Swedish Obese Subjects Study (SOS) showed a reduction in its incidence after bariatric surgery $[8,11,12]$. 
On the other hand, malabsorptive procedures such as Rouxen-Y gastric bypass (RYGB) and biliopancreatic diversion (BPD) carry the risk of protein malabsorption due to changes in gut anatomy and physiology, since the small intestine as the major site of protein absorption is partly bypassed. It is characterized by hypoalbuminemia, edema, alopecia, and asthenia. Protein malnutrition is a complication mainly seen in patients undergoing BPD with an occurrence rate of $7-21 \%$ [13], has, however, also been reported after RYGB with an incidence of $13 \%$ at the 2 -year follow-up [14]. While the typical patient with type 1 diabetes is not commonly regarded as overweight or obese, there is a growing number of patients with type 1 diabetes and morbid obesity who seek treatment by bariatric surgery [15]. In this case report we describe the consequences of bariatric surgery in such a patient.

\section{Case Presentation}

A 49-year old woman (height $157 \mathrm{~cm}$, weight $95 \mathrm{~kg}$, body mass index (BMI) $38.5 \mathrm{~kg} / \mathrm{m}^{2}$ ) with type 1 diabetes since 1983 underwent Roux-en-Y gastric bypass in 2005. In 2017, she was admitted to our hospital due to generalized edema. Her history revealed routine check-ups for bariatric patients including blood tests after an overnight fasting and a urine sample. Amongst others, $\mathrm{A} 1 \mathrm{C}$, creatinine, albumin and albumin-creatinine-ratio were evaluated since 1999. As expected, there was a significant weight loss after bariatric surgery (2005: $122 \mathrm{~kg}$, BMI $49.4 \mathrm{~kg} / \mathrm{m}^{2}$. 2007: $80 \mathrm{~kg}$, BMI $32.4 \mathrm{~kg} / \mathrm{m}^{2}$, \% excess weight loss 69.56 , \% total body weight loss 34.43 ). Over the years, some of the weight was regained. At the time of hospital admission the patient's weight was $95 \mathrm{~kg}$ (BMI 38.5kg/m²). Diabetes control has always been poor (A1C 8.9\% (1999), 8.7\% (2005), 10.3\% (2007), 10.8\% (2017)). The patient was using basal-bolus-therapy with insulin glargine and insulin aspart. She was seen by a specialist for diabetes every three months and had repeatedly courses of instruction, however, diabetes control continued to be poor. Already in 1999 diabetic nephropathy and retinopathy have been diagnosed, only 16 years after first diagnosis. Albuminuria was present before bariatric surgery and increased over the years (albumin/creatinine ratio (ACR) 32.6mg/g (1999), 158mg/g (2005), 2246.4mg/g (2014), $1336.1 \mathrm{mg} / \mathrm{g}$ (2017)). Furthermore, hypoalbuminemia has been present before surgery and deteriorated subsequently (albumin 29.0\% (1999), 60.6\% (2005), 32.2\% (2012), 21.6\% (2017)).

On admission, A1C was $10.8 \%$, serum albumin $40 \%$ (normal range: $55.8-66.1 \%$ ) and ACR was $1336.1 \mathrm{mg} / \mathrm{g}$, Creatinine $2.07 \mathrm{mg} /$ $\mathrm{dl}$, and GFR $25 \mathrm{ml} / \mathrm{min} / 1.7 \mathrm{~m}^{2}$. Subsequently, the patient was substituted intravenously with albumin which caused only a slow regression of edema only. She was advised about the appropriate protein intake for bariatric patients by a trained dietologist and prescribed "Ressource Protein" ${ }^{\circledR}$ (a protein-rich, high-calorie drinking food, containing 18.8gms of protein per bottle) twice a day. During in-hospital treatment a very good diabetes control was achieved. After nearly four weeks of in-hospital treatment the patient could be discharged in good general health. Regular checkups were planned. One year after hospital admission ACR was $1522 \mathrm{mg} / \mathrm{g}$, albumin was $32.9 \mathrm{~g} / \mathrm{l}$, Creatinine was $1.14 \mathrm{mg} / \mathrm{dl}$, and GFR $50 \mathrm{ml} / \mathrm{min} / 1.7 \mathrm{~m}^{2}$.

\section{Discussion}

Although the SOS study demonstrated that patients undergoing bariatric surgery show an improvement of albuminuria [8], these results cannot be generalized. This case report describes the deleterious consequences of malabsorptive bariatric surgery in a poorly controlled patient with type 1 diabetes and already preoperatively existing albuminuria. Regarding the long diabetes duration, persistent poor diabetes control and the already substantially increased albumin excretion, a further worsening of albuminuria and the development of macroalbuminuria and overt renal insufficiency should have been anticipated. In addition, poor diabetes control might indicate a lack of compliance which is necessary for the required follow-up consultations after bariatric surgery. In this patient, hypalbuminemia is most likely the consequence of deterioration of kidney function with development of macroalbuminuria and protein malabsorption following a malabsorptive procedure. In addition, reduced protein intake might be an additional contributing factor.

The course of the disease highlights the need for interdisciplinary consultation between internists/endocrinologists, surgeons, dietitians and psychologists. While there is no absolute contraindication for bariatric surgery in morbidly obese patients with type 1 diabetes, a careful preoperative evaluation is mandatory. This includes screening for diabetes complications, especially nephropathy with increased albumin excretion, and information on patient's compliance regarding regular follow-up and appropriate substitution of macro- and micronutrients as well as vitamins. In patients at risk for hypoalbuminemia due to albuminuria a nonmalabsorptive method such as the sleeve gastrectomy should be considered. This, however, does not preclude hypalbuminemia, taking into account a possibly decreased protein intake due to gastric restriction or loss of appetite.

\section{Acknowledgement}

E-Ch K-made the research and wrote the manuscript. JMBcontributed to the interpretation of the results. BL-supervised the findings of this work. All authors provided critical feedback and contributed to the final version of the manuscript.

\section{References}

1. Stehouwer CD, Smulders YM (2006) Microalbuminuria and risk for cardiovascular disease: Analysis of potential mechanisms. J Am Soc Nephrol 17(8): 2106-2111.

2. Gerstein HC, Mann JF, Yi Q Zinman B, Dinneen SF, et al. (2001) HOPE Study Investigators (2001) Albuminuria and risk of cardiovascular events, death, and heart failure in diabetic and nondiabetic individuals. JAMA 286(4): 421-426. 
3. Cederholm J, Eliasson B, Nilsson PM, Weiss L, Gudbjörnsdottir S, et al. (2005) Microalbuminuria and risk factors in type 1 and type 2 diabetic patients. Diabetes Res Clin Pract 67(3): 258-266.

4. Hovind P, Tarnow L, Rossing P, Jensen BR, Graae M, et al. (2004) Predictors for the development of microalbuminuria and macroalbuminuria in patients with type 1 diabetes: Inception cohort study. BMJ 328(7448): 1105.

5. Krolewski AS, Warram JH, Christlieb AR, Busick EJ, Kahn CR (1985) The changing natural history of nephropathy in type I diabetes. Am J Med 78(5): 785-794.

6. Adler AI, Stevens RJ, Manley SE, Bilous RW, Cull CA, et al. UKPDS GROUP (2003) Development and progression of nephropathy in type 2 diabetes: The United Kingdom Prospective Diabetes Study (UKPDS 64). Kidney Int 63(1): 225-232.

7. Welbourn R, Hollyman M, Kinsman R, Dixon J, Liem R, et al. (2019) Bariatric surgery worldwide: Baseline demographic description and one-year outcomes from the fourth IFSO global registry report 2018. Obesity Surgery 29(3):782-795.

8. Sjostrom CD, Lissner L, Wedel H, Sjostrom L (1999) Reduction in incidence of diabetes, hypertension and lipid disturbances after intentional weight loss induced by bariatric surgery: The SOS intervention study. Obes Res 7(5): 477-484.
9. Sjostrom CD, Lissner L, Sjostrom L (1997) Relationships between changes in body composition and changes in cardiovascular risk factors: The SOS intervention study. Obesity Research 5(6): 519-530.

10. American Diabetes Association (2020) Standards of medical care in diabetes-2020. Diabetes Care, USA.

11. Sjostrom L (2013) Review of the key results from the Swedish Obese Subjects (SOS) trial-A prospective controlled intervention study of bariatric surgery. J Intern Med 273(3): 219-234.

12. Carlsson LMS, Romeo S, Jacobson P, Burza MA, Maglio C, et al. (2015) The incidence of albuminuria after bariatric surgery and usual care in Swedish Obese Subjects (SOS): A prospective controlled intervention trial. Int J Obes (Lond) 39(1): 169-175.

13. Faintuch J, Matsuda M, Cruz ME, Silva MM, Teivelis MP, et al. (2004) Severe protein-calorie malnutrition after bariatric procedures. Obes Surg 14(2): 175-181.

14. Lupoli R, Lembo E, Saldalamacchia G, Kesia Avola C, Angrisani L, et al. (2017) Bariatric surgery and long-term nutritional issues. World J Diabetes 8(11): 464-474.

15. Maffeis C, Birkebaek NH, Konstantinova M, Schwandt A, Vazeou A, et al. SWEET Study Group (2018) Prevalence of underweight, overweight, and obesity in children and adolescents with type 1 diabetes: Data from the International SWEET registry. Pediatr Diabetes 19(7): 1211-1220. 